\title{
THE NON-ACCIDENTAL TOURIST: USING AMBIENT INTELLIGENCE FOR ENHANCING TOURIST EXPERIENCES
}

Sobah Abbas Petersen and Anders Kofod-Petersen Dept. of Computer \& Information Science, Norwegian University of Science \& Technology, Trondheim.NORWAY.E-mail: \{sap, anderpe\}@idi.ntnu.no

\begin{abstract}
An Ambient Intelligent environment is aware of the presence of a person, perceives her needs and responds intelligently. Ambient intelligence can be used to guide a tourist through the city in such a way that is mutually beneficial for both the tourist and the city. The composite set of services delivered to a tourist can be personalized. This adaptive behaviour is best supported by Virtual Enterprises that are formed dynamically, at runtime. This paper considers an Ambient Intelligent scenario from the service providers' perspective and discusses how such scenarios can be realized through Virtual Enterprises.
\end{abstract}

\section{INTRODUCTION}

What might living with Ambient Intelligence (AmI) be like for ordinary people in 2010? The IST Advisory Group (ISTAG) has described a set of futuristic scenarios to address this question, (Ducatel et al. 2001). These scenarios outline the European vision of high-tech development in the field of AmI. One of these scenarios, "Maria", describes a busy business person travelling from Europe to an Asian country that has an AmI infrastructure. Maria's computer and personal communication device is her P-Com, which she wears on her wrist. She leaves the airport, checks in to her hotel and is able to go smoothly through her high-pressure world and concentrate on her work without negotiating each step of the way. The services that are required by Maria are available to her and she can make adjustments and selections as she desires. We are interested in the service providers' perspective of the scenario, in particular, how such scenarios can be realized easily and efficiently, and can be of mutual benefit for the individual as well as the community or the society.

AmI provides the seamless and intuitive support that Maria needs to obtain her services. Her personal communication device and the devices placed in her hotel room infer her needs at any point in time. We have considered the services that were available to her in order to analyse and understand how the scenario can be realized. For example, she has a rental car waiting for her at the airport. To have this service available at the time of her arrival requires the collaboration and coordination among 
several parties such as Maria or her personal agent, her travel agent, rental car company and credit card company. She is guided through the traffic which requires collaboration among the rental car company, traffic guidance authority and the credit card company. Similarly, the hotel booking requires a number of parties working together. All of these services are provided by a number of different parties, with different interests and business goals. They must collaborate, coordinate, exchange information and possibly negotiate to reach an agreement. The possibility of such collaboration is facilitated by the appropriate technical infrastructure and accessibility to the appropriate technologies.

In this paper, we consider a similar scenario where a tourist has a short stopover in the Norwegian city of Trondheim, a city with wireless coverage, and how the experiences of the tourist can be enhanced while supporting the business community and the city of Trondheim. The "Wireless Trondheim" initiative is a collaboration between the local council and the university. We see this as an opportunity for the ordinary person in the city and visitors to the city to enhance their experiences. Similarly, it is also an opportunity for the small and large businesses that are already in the city to enhance their services and increase their customer base.

We have chosen a scenario with tourists as they are likely to be one of the user groups where AmI is initially to be realized in the near future. Also a person travelling for any purpose may be a tourist and tourists are more likely to be open to new suggestions and explorations of what a city may have to offer. We consider the needs of the tourist along with the mutual needs of the city.

Virtual Enterprises (VE) are a promising business model for providing services as envisaged in the ISTAG scenario. We discuss the role and significance of VEs in this context and why VEs are a suitable means of realising AmI. The rest of the paper is organized as follows: Section 2 defines AmI, Section 3 describes our scenario, Section 4 analyses the scenario, Section 5 discusses the service providers in an AmI scenario as VEs and Section 6 proposes a functional system architecture for realising our scenario.

\section{AMBIENT INTELLIGENCE}

The concept of AmI has been described as human beings surrounded by intelligent interfaces supported by computing and networking technology that is embedded in everyday objects such as furniture, clothes and the environment (ISTAG 2005). The environment should be aware of the presence of a person (the user) and perceive the needs of the person and respond intelligently to these needs. It should be able to adapt to the needs of the user in a relaxed and unobtrusive manner.

The above description of AmI suggests some requirements for the success of it. There must be some technology that is accessible to the user or serves the user in a proactive yet unobtrusive manner (Weiser and Brown 1997), becomes aware of the user and her needs and responds intelligently to the context and needs of the user. We see AmI as an overlap of a number of paradigms; Ubiquitous Computing (Weiser 1991), Pervasive Computing (Satyanarayanan 2001) and Artificial Intelligence (Russel and Norvig 2002). The Ubiquitous Computing aspect addresses the notion of accessibility of the technology, where the technology and connectivity is available through everyday objects that are in the user's environment. Artificial Intelligence techniques provide the context awareness to establish the user's needs 
and the appropriate response and the Pervasive Computing aspect supports the architectural aspects to realize the situation.

$\mathrm{AmI}$ is often discussed from the perspective of the user, where the user is a human being. Obtaining the relevant information about the user's needs and establishing this constitutes a major part of this. Responding accordingly and the delivery of the appropriate services to meet the user's needs is a challenge that is gaining interest, e.g. (Myrhaug and Göker 2003). This requires an analysis of the user's needs from a service providers' perspective and addressing how two or more service providers can collaborate to do this.

\section{TOURIST IN TRONDHEIM}

Consider the scenario where a tourist arrives in Trondheim on a cruise ship. The cruise ship stops over in the Trondheim harbour for one day and the passengers have the opportunity to visit Trondheim, see some of the sights and museums and buy some souvenirs. Before leaving the cruise ship, the tourist signs on to the "Trondheim Experience", which provides her a mobile device such as a PDA or a smartphone. The harbour is $1 \mathrm{~km}$ from the city centre. The tourist leaves the cruise ship and walks towards the city centre. She is faced with some street signs, e.g. "sentrum", "pirbadet", and "solsiden". She accesses the glossary service using her device to get an explanation of these signs. She follows the signs that say sentrum to the city centre.

She passes Nidarosdomen, the cathedral in the city. She is presented a brief introduction to the landmark and is informed that there is a guided tour of the cathedral starting in 10 minutes. The cost of an entrance ticket and the directions for obtaining a ticket are provided. As she joins the guided tour of the cathedral, the Trondheim Experience service de-activates itself. She chooses to utilize a locationdependent guide installed in the cathedral, (Wang et al. 2005). As she leaves the cathedral, the Trondheim Experience service re-activates and she is informed that there is a concert in the cathedral at 16:00hrs, the ticket prices and how to obtain a ticket. She is prompted with two package offers; (i) to see the concert at the cathedral, visit the museum at the Archbishop's residence a few metres from the cathedral, a traditional Norwegian meal at a restaurant and transport back to her cruise ship after the concert, (ii) to walk to Skyssstasjon, which is a restaurant in one of the city's oldest buildings, a walk along Bakklandet, a trip to the island outside Trondheim, Munkholmen, and transport back to her cruise ship. She wonders if some of her fellow passengers who are also visiting the city would like these offers and forwards the offer to the other passengers that signed on for the Trondheim Experience service.

In order to utilize the limited time she has in Trondheim and enjoy the city rather than finding out what's on offer, she accepts the first offer and plans the rest of her day. She visits the museum at the Archbishop's residence and continues walking around the city centre until the time to go to the restaurant. As she passes various buildings and shops, she is informed about the architecture and history of the building and about sales and offers in the shops, depending on her interests. Also, she is able to find out who will be joining her for the concert and the traditional Norwegian meal. 


\section{ANALYSIS}

The scenario described in the previous section establishes a tourist's needs and proposes some services. The tourist can ask for a specific service, for examples, the glossary service for explanations of street signs. However, the AmI component is mainly aimed at establishing the tourist's needs based on information available from the tourist, patterns of needs by previous users as well as what can be detected automatically, such as location and time (e.g. date, time of the day and season). The tourist is provided a set of services based on this. In addition to providing information that is directly relevant there and then, the tourist is also prompted with other potential services, e.g. the package including a museum and a meal. The tourist is also able to communicate with other tourists that use the same service. The services provided respond to a possible need as well as try to stimulate the user for possible needs in the near future.

Consider the user's perspective, in this case the tourist. The tourist would like to see and learn as much about the city as possible within the time that is available, i.e. one day. As the tourist walks around the city, she may wish to know about the architecture of the buildings, where to find specific items and souvenirs, listen to some local music and taste traditional food. Finding out these things is time consuming and joining a guided tour of the city can be constraining. The tourist who likes to walk around the city and see the sights and learn about the city would like a combination of the guided tour and a free walk, i.e. a personalized guided tour.

Consider the service provider's perspective, in this case the local businesses and the city of Trondheim. The city of Trondheim would like the tourist to have a good time, form a positive impression of the city and attract the tourist for a visit in the future. At the same time, it would like the tourist to visit the historical sights of the city, contribute to the maintenance of these by purchasing entrance tickets and souvenirs. The local businesses would like the tourist to visit their shops or restaurants and use their services, thus increasing their customer base and the volume of business they conduct. Rather than leaving the tourist to accidentally stumble upon what the city has to offer, the city could collectively be proactive in guiding the tourist through the parts of the city that suits the tourist's preferences. The number of parties that are interested in meeting the needs of the tourist and stimulate more needs from the tourist while enhancing their own business prospects is huge and varied. To achieve optimal benefit from this situation, the service providers need to collaborate and form alliances or VEs to provide a set of services to the tourist.

AmI establishes a user's needs while a VE can be used to meet the needs of the user. AmI focuses on the user's perspective of the situation while a VE is seen from a service provider's perspective.

\section{SERVICES PROVIDERS AS VIRTUAL ENTERPRISES}

We consider a VE as a set of entities, such as organizations, human beings or software agents that collaborate to achieve a specific goal (Petersen and Gruninger 2000). A VE can be characterised as a partnership of enterprises that collaborate as a temporary network, (Jagdev and Browne 1998), by sharing their skills, costs and 
risks. This network may consist of pre-existing enterprises that collaborate by means of specific Information Technology components (Garita and Afsarmanesh 2001). They align their goals and commit to achieving these goals through a process of negotiation. VEs are usually formed to exploit a market opportunity (Fischer et al. 1996), and their dynamic and flexible nature facilitates the quick and easy formation as well as adaptation to the market situation.

To provide the services in an AmI environment, a number of entities must collaborate behind the scenes. We believe that VEs are necessary for providing services that are seamless and cohesive in an AmI environment. The dynamic and flexible nature of VEs facilitates the adaptation to the user's needs. The relationship between AmI and VE is illustrated in Figure 1.

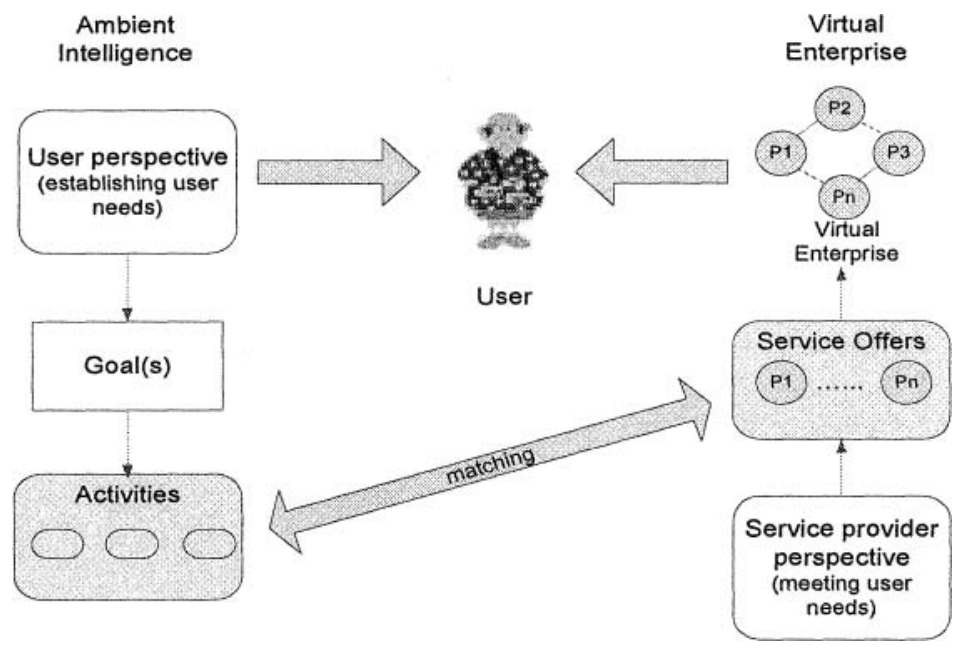

Figure 1: Relationship between Ambient Intelligence and Virtual Enterprises

A tourist's situation and desires, established by AmI, can be modelled as a set of goals that need to be fulfilled. Using ideas from Enterprise Modelling, goals can be achieved by performing a set of activities (Petersen and Gruninger 2000). The identification or the selection of the set of appropriate activities that best fulfils the goals can be done by reasoning.

Service providers in the city who are interested in serving the tourists are transmitting information about themselves as service offers. Some of these service providers, e.g. P1, P2, P3 and Pn as shown in Figure 1, could perform the set of activities that fulfil the goals. Thus, the response to the tourist's needs as a set of activities can be proposed by a group of partners that collaborate, i.e. a VE, to deliver a set of services. For example, the museum at the Archbishop's residence, the concert organizer, the restaurant and the taxi company form a VE to propose the first offer to the tourist. The tourist can pay for this package offer as a single product without negotiating with each service provider individually. Once this is accepted by the tourist, the VE needs to deliver the services and the mobile device guides her through the city to reach the goals that have been set, while continuing to dynamically assess possible changes in her needs. 
In order for such VEs to form, each service provider must provide information about their offers, their interests, who they wish to collaborate with and other relevant information. This information can be used first to match against the requirements for performing the activities and second, to form an appropriate team of partners that constitute the VE. An example of such a VE formation model and supporting infrastructure are described in (Petersen et al. 2003).

\section{SYSTEM DESIGN}

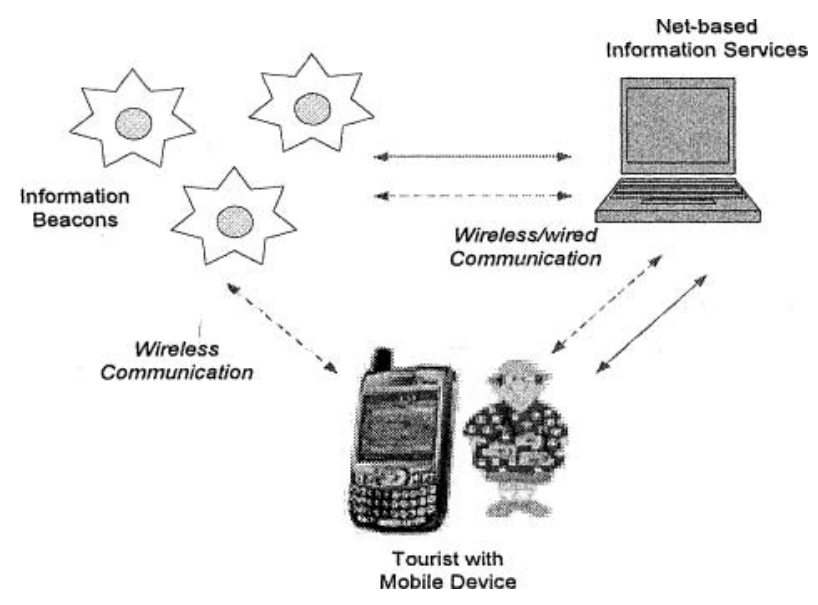

Figure 2: Functional System Architecture

To realize the tourist scenario, we envisage a system that takes into account the runtime context information for the tourist's needs, such as location, availability of services, as well as utilize information about past experiences and tourist's preferences. Reasoning capabilities can be used to establish the needs as well as to determine the services to offer. Based on the experiences from the AmbieSense project, (AmbieSense 2005) and (Kofod-Petersen and Mikalsen 2005(a)), a functional systems architecture for realising our scenario is shown in Figure 2. The tourist has a device that detects location. A net-based information service contains previous experiences and reasoning capabilities. Service providers submit their information to the information services using information beacons, e.g. (KofodPetersen and Mikalsen 2005(b)). The communication via the different entities can be wireless.

Establishing the tourist's needs/perception: the first step is to understand something about the tourist's interests. When she signs up for the Trondheim Experience service, she is asked to select some keywords that indicate her interests, e.g. medieval Trondheim, Norwegian food, shopping. In order to personalize the services offered to the tourist, a profile of the tourist must be established. A good candidate for constructing user models is through stereotypes as reported in (Jayaputera et al. 2003). This requires some form of reasoning. Why was the tourist prompted about the guided tour of the cathedral? One reason could be that she is currently in that location. Why was she offered the two specific packages for 
experiencing Trondheim? The selective offers can be based on what is known about the tourist, e.g. her interest in medieval Trondheim and Norwegian food and what tourists that have used the Trondheim Experience service in the past with similar interests have desired. Reasoning capabilities facilitate the personalization of the information and services offered to the tourist.

The net-based information services determine the information that should be presented to the tourist based on her needs. Since the tourist has signed on for the Trondheim Experience, we assume that she is interested in receiving some information and service offers. She can choose to receive personalized information or all information that is available (e.g. which may include some advertising information) and she can selectively turn the service on an off.

Service offers/personalized response: The services that are available for any context can be provided by a predefined model of the city. A more dynamic way of doing this is the use of information beacons in the city that provide runtime information to the system about the services that are currently available in and around any location, see Figure 2. Thus, the service providers transmit information about themselves using the information beacons. The use of information beacons by the service providers allow them to control the information that they publish about themselves and be selective about their audience. This allows the service providers the opportunity to submit their information and offers, if and when they desire, and to selected groups of users based on the user profile. For example, a shop selling scuba diving equipment may not desire to send information to a tourist that is interested in medieval Trondheim. Based on this information, reasoning capabilities in the system can be used to provide a response that is appropriate for the current situation, i.e. a personalized response.

Information services/reasoning: the information services that both the mobile device and the information beacons are connected to are capable of reasoning to establish the user's needs based on available information. The system establishes a profile of the tourist and determines the type of user she is. Then it will answer questions such as which offers shall we propose to the tourist? Once the tourist accepts a package, the goal of the system is to lead the tourist through the city to utilize the services that have been purchased. While traversing through this path, the system finds opportunities to propose other services to the tourist such as information about the architecture of a building and sales offers. Again, the tourist can choose to receive this information.

\section{SUMMARY}

VEs provide a promising business model for realising AmI scenarios. This paper describes the scenario of a tourist in a wireless city, who can be provided a personalized city guide via AmI. The tourist's needs are established using AmI and the needs are met by a group of service providers that collaborate as a VE. We have discussed the relevance of VEs for realising AmI scenarios and proposed the design of a system that facilitates such scenarios.

The ideas presented in this paper describe an innovative use of VEs to provide rich and personalized user experiences. Its main contribution is to propose means of realizing AmI where the business and societal perspectives are considered. As discussed, AmI is realized by the collaboration of several entities or service 
providers and VEs are a promising means of providing seamless and cohesive services in an AmI environment.

\section{ACKNOWLEDGEMENT}

The ideas presented in this paper are inspired by the work done in the projects MOTUS2, supported by the Norwegian Research Council, and AmbieSense, (EU project IST 2001-34244).

\section{REFERENCES}

1. AmbieSense 2005, Available from http://www.ambiesense.net

2. Ducatel K, Bogdanowicz B, Scapolo F, Leijten J, Burgelman J-C. Scenarios for Ambient Intelligence in 2010, Final Report, IPTS-Seville, 2001.

3. Fischer K, Müler J, Hemmig I, Scheer AW. Intelligent Agents in Virtual Enterprises. In Proc. of 1st International Conference on the Practical Applications of Intelligent Agents and Multi-Agent Technology (PAAM-96), London, U.K.

4. Garita C, Afsarmanesh H. A Study of Information Management Approaches for Support Infrastructures. COVE Newsletter (1), 2001.

5. ISTAG, Ambient Intelligence: from Vision to Reality, in Ambient Intelligence, Lakatta Riva G, Vatalaro F, Davide F, Alcañiz M (Eds.), IOS Press, 2005.

6. Jagdev HS, Browne J. The Extended Enterprise - A Context for Manufacturing. International Journal of Production Planning and Control, 9(3), pp. 216-229.

7. Jayaputera G, Alahakoon O, Cruz LP, Loke SW, Zaslavsky AB. Assembling Agents On-Demand for Pervasive Wireless Services, Wireless Information Systems, Ed. Mahmoud QH, ICEIS Press, 2003.

8. Kofod-Petersen A, Mikalsen M. An Architecture Supporting implementation of Context-Aware Services. In Proc. of Workshop on Context Awareness for Proactive Systems (CAPS 2005), Eds. Florén P, Lindén G, Niklander T, Raatikainen K. Helsinki, Finland June 2005 (a).

9. Kofod-Petersen A, Mikalsen M. Context: Representation and Reasoning - Representing and Reasoning about Context in a Mobile Environment. Revue d'Intelligence Artificielle, 2005(b), 19(3):479-498.

10. Myrhaug HI, Goker A. AmbieSense - Interactive Information Channels in the Surroundings of the Mobile User. In Univeral Access in HCI, 10th International Conference on Human-Computer Interaction, Eds. Stephanidis C, Lawrence Erlbaum Associates, 2003, pp. 1158-1162.

11. Petersen SA, Gruninger M. An Agent-based Model to Support the Formation of Virtual Enterprises. International ICSC Symposium on Mobile Agents and Multi-agents in Virtual Organizations and E-Commerce (MAMA 2000), in Woolongong, Australia, 11-13 Dec. 2000.

12. Petersen SA, Rao J, Matskin M, Virtual Enterprise Formation with Agents - an Approach to Implementation, IEEE/WIC International Conference on Intelligent Agent Technology, IAT2003, Halifax, Canada, October 2003, pp. 527-530.

13. Russel SJ, Norvig P. Artificial Intelligence: A Modern Approach. Prentice Hall, 2nd Edition, 2002.

14. Satyanarayanan M. Pervasive Computing: Vision and Challenges. IEEE Personal Communications, $2001,8(4)$, pp. 10-17.

15. Wang AI, Sørensen C, Brede S, Servold H, Gimre S.: The Nidaros Framework for Development of Location-aware Applications, In Proc. 2nd IFIP TC8 Working Conference on Mobile Information Systems - 2005 (MOBIS'2005), Leeds UK, 5-6 December 2005, pp. 171-186.

16. Weiser M. The computer for the 21st century. Scientific American, Sept. 1991, pp. 94-104.

17. Weiser M, Brown JS. The Coming Age of Calm Technology. In Beyond Calculation: The Next Fifty Years of Computing, Eds. Denning PJ, Metcalfe RM. Springer-Verlag, 1997, pp. 75-85. 